\title{
Prevalence of Iodine deficiency disorder in a highland district in Tigray
}

\author{
Teklay Kidane ${ }^{1}$, Aregai Woldegebriel ${ }^{2}$
}

\begin{abstract}
A cross-sectional community based goiter prevalence survey was conducted in February 2003 in Neksege Sub District in Tigray to collect baseline data on the magnitude of Iodine Deficiency Disorder (IDD) and the demand for iodinated salt supplementation. The community prevalence of goiter was $71.4 \%$, with $59.5 \%$ in males and $80.2 \%$ in females. Adjusted community goiter prevalence was $57.2 \%$. The lowest estimated rates of cretins were 37.7 per a thousand people. Goiter is rampant and epidemiological estimates of other IDD manifestations are unacceptably high and call for urgent intervention. [Ethiop.J.Health Dev. 2006;20(1):58-59]
\end{abstract}

\section{Introduction}

Inadequate supply of iodine has a negative effect on the growth and development of human beings and animals. These effects are collectively called Iodine Deficiency Disorders (IDD). The disorder comprises of goiter, abortion, stillbirth, increased prenatal and infant mortality and neurological deficits (1). A nation wide study of goiter prevalence undertaken between March 1980 and July 1981 showed a gross goiter prevalence of $30.6 \%$ and $18.7 \%$ among school children and household members respectively (2).

The objective of this study was to determine the prevalence of goiter and estimate the prevalence of other manifestations of IDD using epidemiological models as baseline for intensified intervention.

\section{Methods}

The study was conducted in Neksege, which is a subdistrict in EndaMohoni District, in Tigray Region. Three posts/tabias in Tigrigna/ and 12 villages comprise the sub-district, a mountainous area that has a total population of 17,578. The target population for the goiter survey was the entire population of the semi-urban sub district capital. On February 21, 2003, four physicians visibly inspected and palpated thyroid glands, and graded on standard survey forms. Thyroid glands graded IA to III were defined as goiter, while visible goiter was defined by grades II and III.

0: no goiter

IA: goiter palpable, but not visible

IB: goiter easily visible when neck extended

II: goiter visible without extension of the neck

III: large goiter visible from a distance

The adjusted Total Goiter Rate was calculated using total population as a denominator to adjust prevalence figures to account for incomplete survey coverage of the population. The models used in the Ethiopian National Goiter Survey of 1980 (2) were used to estimate cretinism prevalence per 1000 population.

$$
c_{g}=\exp \left(b_{0}+b_{i} g+b_{i i} g^{2}\right) /\left[1+\exp \left(b_{0}+b_{i} g+b_{i i} g^{2}\right)\right]
$$

where: $c_{g}$ is prevalence (proportion) of cretinism estimated from the prevalence of gross goiter, $g$ is the prevalence (proportion ) of gross goiter, $b_{0}=-9.3939, b_{i}=$ $15.796, b_{\mathrm{ii}}=-8.8026$

Rates per 1000 live births of reproductive losses including neonatal death, stillbirth, and miscarriage/ infertility were estimated as:

$l_{\mathrm{n}}=\mathrm{m}_{\mathrm{n}} \mathrm{c}_{\mathrm{g}}$

where: $\mathrm{m}_{\mathrm{n}}$ is multiplier for $l_{\mathrm{n}}, \mathrm{c}_{\mathrm{g}}$ is prevalence (proportion) of cretinism estimated from the prevalence of gross goiter. $l_{\mathrm{i}}$ is the rate of neonatal death $\left(\mathrm{m}_{\mathrm{i}} 0.602\right), l_{\mathrm{ii}}$ is the rate of stillbirths $\left(\mathrm{m}_{\mathrm{ii}} 0.656\right)$, and $l_{\mathrm{iii}}$ is rate of miscarriage/ infertility $\left(\mathrm{m}_{\mathrm{iii}} 0.883\right)$.

\section{Results}

Of the 946 sub-district capital residents, 755 (79.5\%) were examined for goiter. Unadjusted goiter prevalence was $71.4 \%$, with $59.5 \%$ in males and $80.2 \%$ in females $(p<0.001)$. Goiter prevalence increased with age in females until age 50 years, while in males, the prevalence peaked at 15-19 years and then declined steadily (Figure 1). The adjusted goiter prevalence was $57.2 \%$. For the adjusted goiter prevalence, the estimated rates per 1000 population of iodine deficiency cretins were 37.3 , lowest estimated rates per 1000 live births of IDD related neonatal death, stillbirth, miscarriage/infertility were $22.7,24.8$ and 33.4 respectively.

\footnotetext{
Discussion

The $71.4 \%$ community prevalence of goiter found in this study is higher than that reported from the National Household Goiter Survey. This may be because Neksege has an isolated community, where residents eat only what is locally produced. The 37.7 per 1000 population estimated cretinism prevalence in Neksege was also found to be very high compared to the 1.17 per 1000
}

${ }^{1}$ Federal Ministry of Health, Family Health Department, P.O. Box 2669, Addis Ababa, Ethiopia; ${ }^{2}$ Tigray Region Health Bureau, Disease Prevention and Control Department, P.O. Box 7, Mekelle, Ethiopia. 


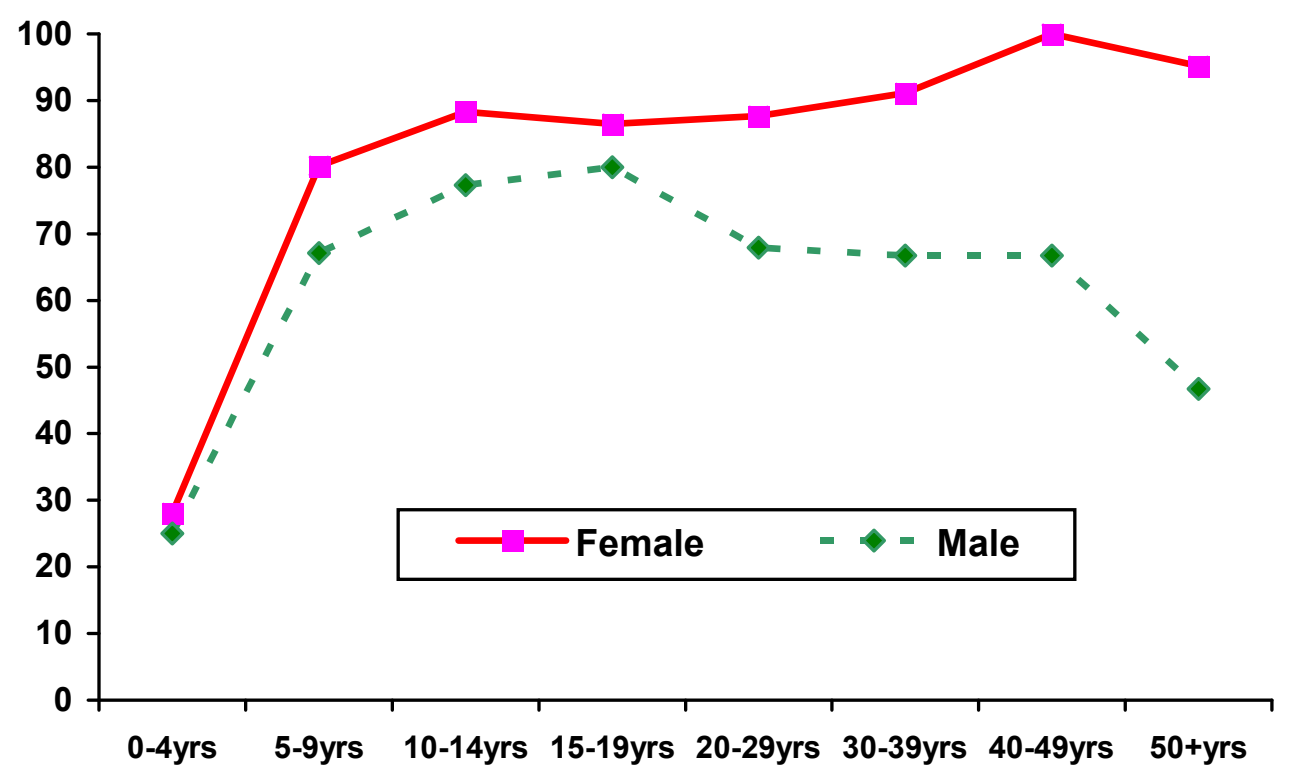

Figure 1: Prevalence of goiter by age group and sex in Neksege, 2003.

population found in the National Goiter Survey (2). The estimates of reproductive loss were also high compared to the national estimates, but were similar to the estimates from the Southeast Asian countries of Nepal, Bhutan and India (1).

Communities with a total goiter prevalence (TGR) above $29.9 \%$ in school-aged children are considered to have severe IDD and correction of the iodine deficiency is considered urgent.

Children under 15 years of age in such regions are at significant risk of permanent physical and mental retardation (3), and should be treated with iodine oil supplementation. In such areas women of reproductive age and pregnant women are also targets for iodine oil supplementation to prevent cretinism in newborns (1). This study reveals IDD to be a serious public health problem in Neksege warranting immediate action. Ideally, iodine oil supplements should be given as an urgent measure to women of reproductive age and to children, while action is taken to increase the distribution of iodated salt to the community. Iodized oil and salt programs are not mutually exclusive. They are complementary. In Lesotho iodized salt coupled with iodine oil supplementation was found to be effective in controlling IDD in remote areas (4).

\section{Conclusion}

Goiter is rampant, and the epidemiological estimates of other IDD manifestations are unacceptably high in
Neksege. We recommend better IDD awareness creation through local education by $\mathrm{CHWs}$, health professionals and teachers, targeting remote and inaccessible highland areas with high goiter rates for iodated oil supplementation, facilitating iodated salt transport by animals, and subsidizing iodated salt prices to make it equal in price with the market price of locally available non- iodated salt.

\section{Acknowledgment}

We thank the Neksege sub-district tabia leaders, health professionals, and community health agents for their help in the study. We also thank EndaMohoni Wereda Health Office staff and administration for their support and assistance.

\section{References}

1. Hetzel BS. The story of iodine deficiency: An international challenge in nutrition. Oxford University Press, New York, USA. 1989.

2. Wolde Gebriel Z, Demeke T, West CE, Vander Haar F. Goiter in Ethiopia. British Journal of Nutrition. 1993;69:257-268.

3. World Health Organization. Elimination of iodine deficiency disorders in South East Asia. Report of a Regional Consultation, New Delhi, India, May 1997.

4. Sebotsa MLD, Dannhauser A, Jooste PL, Joubert G. Prevalence of goiter and urinary iodine status of primary-school children in Lesotho. Bulletin of the World Health Organization. 2003;81(1):28-34. 
